\title{
Habitat use and activity patterns of female Deacon Rockfish (Sebastes diaconus) at seasonal scales and in response to episodic hypoxia
}

\author{
Leif K. Rasmuson $($ Mathew T. O. Blume • Polly S. Rankin
}

Received: 1 July 2020 / Accepted: 11 April 2021 / Published online: 26 April 2021

(C) The Author(s) 2021

\begin{abstract}
We combined a high-resolution acoustic telemetry array with presence/absence receivers to conduct a preliminary study of the seasonal movements, activity patterns, and habitat associations of the newly described Deacon Rockfish (Sebastes diaconus). Eleven mature female Deacon Rockfish were tagged and monitored during an 11-month period, at a nearshore rocky reef off Seal Rock, Oregon, USA, an area of recurring seasonal hypoxia (defined as dissolved oxygen concentration $[\mathrm{DO}]<2 \mathrm{mg} \mathrm{l}^{-1}$ ). Two tags were detected leaving the study area by day 35 , indicating predation or emigration. Three tags became inactive within the array, indicating tag loss or fish death. Six "resident" fish inhabited the array for 246-326 days. Resident fish exhibited high site fidelity, small home ranges (mean $95 \% \mathrm{KDE}=4907 \mathrm{~m}^{2}$ ), and consistent activity patterns for the duration of the summertime high-resolution array (5 months), except during seasonal hypoxia. Resident fish were strongly diurnal in summer, with high levels of daytime activity above the bottom in relatively rugose habitat, followed by nighttime rest periods in deeper, less rugose habitat. During summertime hypoxia, resident fish exhibited less daytime activity during daytime hours with no rest periods at night, inhabited shallower water depths, and moved well away from their core activity areas on long, erratic forays. During the winter, diel patterns were less evident with higher activity levels
\end{abstract}

L. K. Rasmuson $(\bowtie) \cdot$ M. T. O. Blume $\cdot$ P. S. Rankin Oregon Department of Fish and Wildlife, Marine Resources Program, Hatfield Marine Science Center, Newport, OR, USA e-mail: leif.k.rasmuson@odfw.oregon.gov at night (than in the summer) and lower activity levels in the day (than in the summer). We propose that some Deacon Rockfish continuously inhabit nearshore reefs throughout the year, but that daily/seasonal movement patterns, seasonally occurring hypoxia, and prey preferences for planktonic organisms influence relocation.

Keywords Sebastes diaconus - Acoustic telemetry . Movement $\cdot$ Behavior $\cdot$ Hypoxia $\cdot$ Seasonal $\cdot$ Planktivores

\section{Introduction}

The spatiotemporal scales of movement patterns for marine fishes are highly variable (Pittman and McAlpine 2003), with tunas and other large pelagics making migrations on the order of thousands of kilometers (Galuardi et al. 2010; Kraus et al. 2011) and other organisms remaining relatively sedentary in a singular spot (Bryars et al. 2012; Buston 2004). The temporal scales over which these movements occur vary widely from ontogenetic movements such as salmon and eels (Hansen et al. 1993; van Ginneken et al. 2005) to daily vertical migrations in sand lances and lanternfish (Engelhard et al. 2008; Dypvik et al. 2012). Fish movements vary within the same genera leading to niche partitioning (Sbragaglia et al. 2019). Movement can even differ within the same species resulting in distinct behavioral differences (e.g., for size, sex differences, reproductive behavior, etc.; Bell and Sih 2007; Barnett et al. 2011). Understanding intraspecies behavioral plasticity, especially within a habitat occupied by multiple 
species, is ecologically necessary to understanding resource allocation (Leggett 1977; Hays et al. 2016). Further, in the event that the species are caught in fisheries, understanding the movement dynamics, especially in mixed stock fisheries, is essential for sustainable management (Peer and Miller 2014; Ogburn et al. 2017).

Oregon's nearshore recreational fisheries primarily target schooling rockfish inhabiting nearshore rocky reefs. These schools are predominantly composed of Black Rockfish (Sebastes melanops), Blue Rockfish (Sebastes mystinus), and the newly described cryptic species Deacon Rockfish (Sebastes diaconus) (Frable et al. 2015). Although much is known about the movements of Black Rockfish, Blue and Deacon Rockfish have only recently been recognized as separate species, and little is known about their movements in Oregon (Parker et al. 2007; Parker et al. 2008).

In contrast to Black Rockfish, which are consistently captured throughout the year off the central Oregon coast, Deacon Rockfish are often nearly or completely absent from summer catches for weeks or months, causing fishers and managers alike to suspect seasonal and/ or ontogenetic migration away from nearshore reefs (Dick et al. 2017; C Heath, pers. comm). An alternative to the seasonal and/or ontogenetic migration hypothesis is that catchability varies seasonally, and Deacon Rockfish remain at nearshore reefs throughout the year. Whether or not Deacon Rockfish migrate has distinct ecological implications, which in turn affect how to manage fisheries for this species. In additional to seasonal movements, some rockfish are hypothesized to exhibit diel shifts in their behavior. Black Rockfish have been shown to make large vertical movements associated with sunrise and sunset (Parker et al. 2008) whereas Copper Rockfish (Sebastes caurinus) and Quillback Rockfish (Sebastes maliger) exhibited home range movements associated with tidal flow in the Puget Sound (Tolimieri et al. 2009). A complete understanding of the inter- and intra-reef movement of Deacon Rockfish on daily and monthly timescales is important for fisheries management (Crossin et al. 2017). Specifically, managers increasingly seek non-lethal, spatially extensive surveys, making knowledge of seasonal fish locations essential to survey design (Berger et al. 2015; Berger et al. 2017).

Periodic variability in the abiotic environment of a fish can also impact its health and behavior in complex ways, altering normal activity and movements (Gray et al. 2002; Grantham et al. 2004). Oregon coastal waters are subject to seasonal hypoxia (dissolved oxygen $[\mathrm{DO}]<2 \mathrm{mg} \mathrm{l}^{-1}$ ) in the upwelling favorable summer months, the varied effects of which have been documented for other species of rockfish, but not for Deacon Rockfish (Diaz and Rosenberg 1995; Hopkins et al. 1995; Rankin et al. 2013). Responses to hypoxia can lead to fish dispersal or fish concentration, but have also been shown to affect home range, site fidelity, and refuge-seeking behavior in Rockfish (Pihl et al. 1991; Rankin et al. 2013). Changes in environmental conditions can result in fish remaining within an area, but cause fish to be behaviorally or physically "unavailable" to fishery capture or survey, or alternatively may make fish more susceptible to capture in a fishery (Hannah and Blume 2016; Stanley et al. 1999). As managers often use catch rates as a proxy for fish abundance, knowing the level of environmental influence on fish behavior is essential.

Investigating the movements of Deacon Rockfish over time, and throughout a range of environmental conditions, can provide much-needed data on their natural history, responses to changing environmental conditions, and can inform survey design. Determining the scale of movements for initial study design can be challenging for Rockfish as movements for reef inhabitants may range from high site fidelity over periods of months or years for some species ( $S$. melanops, $S$. maliger) to the wide-ranging Canary Rockfish (Sebastes pinniger) (Parker et al. 2007; Hannah and Rankin 2011). Acoustic telemetry is an effective tool for establishing baseline movements and behavior of tagged fish, while providing scale of movements to inform the design of more comprehensive investigations. The goal of this study was to use high-resolution acoustic telemetry combined with simple presence/ absence data to track Deacon Rockfish over a one-year period to: (1) provide preliminary scales of movement, (2) describe daily and seasonal patterns of behavior and use of habitat, and (3) examine the relative influence of seasonal hypoxia on movements, behavior patterns, and habitat usage.

\section{Materials and methods}

Study site and Array

The Seal Rocks study area, on the central Oregon coast, encompassed $11.84 \mathrm{~km}^{2}(2.86 \mathrm{~km} \times 4.14 \mathrm{~km})$ of 
nearshore rocky reef. The study area was comprised of bedrock benches, boulders, and rocky pinnacles for which $2 \times 2 \mathrm{~m}$ multibeam resolution and side scan bathymetry data was available (Fig. 1). The primary habitat was variably rugose with swaths of smaller, complex secondary habitat in between. Specifically, our study area included an isolated rocky reef ranging in depth from 12 to $26 \mathrm{~m}$ that could be surrounded by a perimeter of receivers in low-relief habitat, to detect fish traveling beyond the reef. Results of a 15-day range testing study (conducted in the most rugose, high-relief area of the reef) provided worst-case detection statistics through a range of swell and wind conditions. The results suggested an optimal receiver spacing of $250 \mathrm{~m}$ (see online supplement for more information).

$124^{\circ} 6^{\prime} \mathrm{W}$

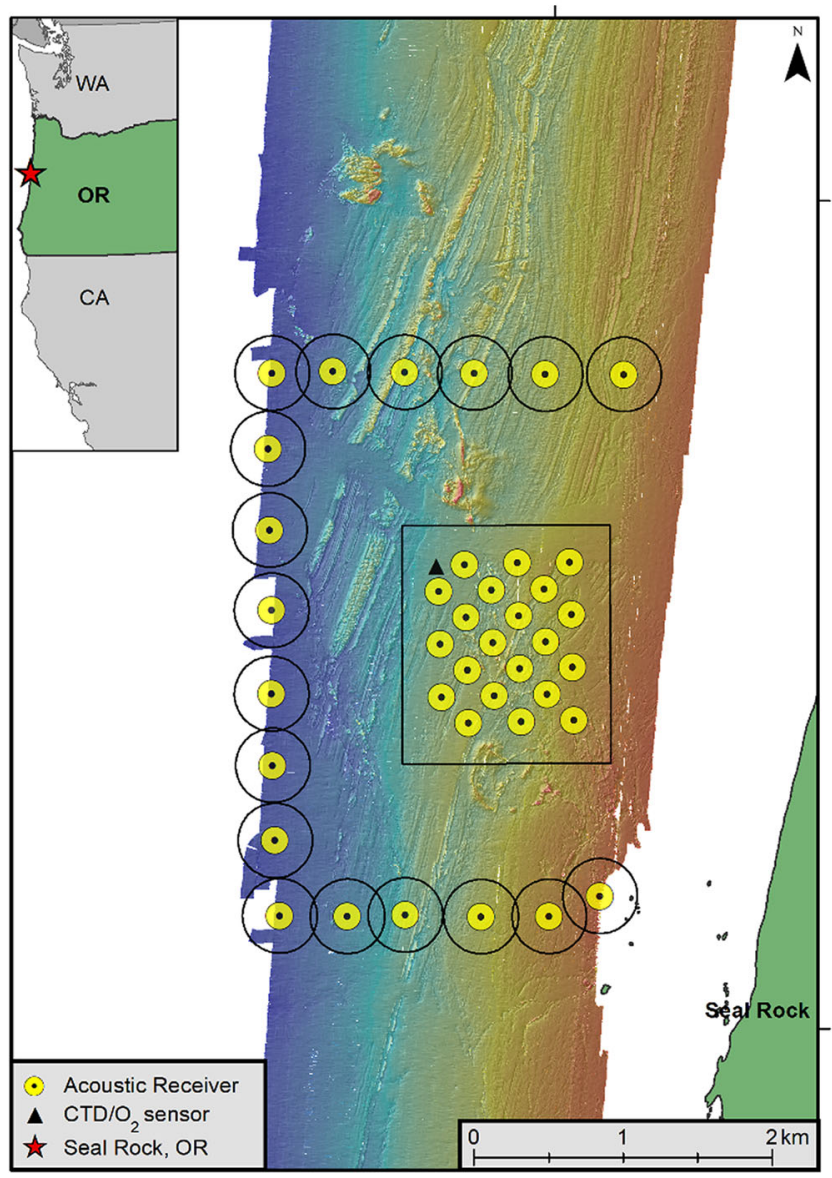

Fig. 1 Study area off Seal Rock, Oregon, showing bathymetry and locations of moored receivers and CTD. Left panel is the summertime high-resolution VPS (VEMCO Positioning System) acoustic receiver array with co-located synctags (square box indicates VPS area of acoustic detection) with the perimeter receiver "fence." Right panel is the non-VPS winter array used for
Based on these findings, and in consideration of habitat, ocean conditions, and potential range of travel for fish, we used two different acoustic telemetry array designs to maximize tag detections during both summer and winter periods (Andrews et al. 2011). The highresolution summer array (May-September, 2016) included an inner grid of VPS (VEMCO Positioning System) receivers, surrounded by an outer perimeter fence of receivers used to detect any fish leaving the area (Fig. 1). The inner grid encompassed a $2.23-\mathrm{km}^{2}$ reef area to acquire fine-scale movements and habitat association, and was comprised of $21 \mathrm{VR} 2 \mathrm{~W}$ receivers with co-located V16 coded synchronization tags (synctags, V16T-4L and V16-4L) moored at $250 \mathrm{~m}$ spacing to allow tag transmissions to be detected by

\section{$124^{\circ} 6^{\prime} \mathrm{W}$}

$44^{\circ} 33^{\prime} \mathrm{N}$

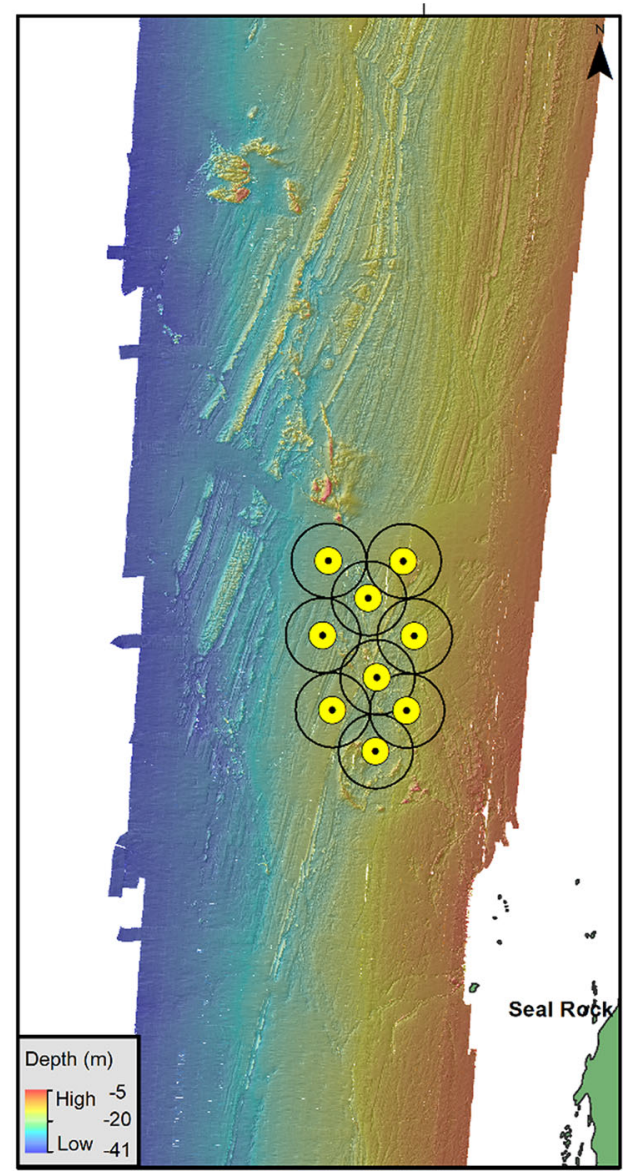

presence/absence-only detection. Black circles indicate $250 \mathrm{~m}$ detection range for receivers used for presence/absence detection. Inset is the Washington, Oregon, and Northern California coastlines. Star in Oregon is the Seal Rocks study area. Triangle indicates the position of the moored CTD with oxygen sensor 
multiple receivers. Also moored were two permanent, centrally located V16 reference tags (VEMCO, Nova Scotia, Canada). Synctags are acoustic transmitters used for time synchronization that allow calculation of triangulated positions for each fish (VEMCO, Nova Scotia, Canada). This system can provide accurate $(5-15 \mathrm{~m})$ position information but only for a relatively small number of tagged fish, due to the high density of synctag transmissions (VEMCO, Nova Scotia, Canada). Acoustic receivers and synctags were positioned 3 and $4 \mathrm{~m}$ off bottom, respectively. The 18-receiver perimeter fence was $9.74 \mathrm{~km}$ long, positioned $1200 \mathrm{~m}$ outside of the VPS array, and surrounded the north, west, and south side of the array (excluding the shallow shoreline side). Perimeter fence moorings were placed $500 \mathrm{~m}$ apart for presence/absence detection by a single receiver, in depths ranging from 12 to $39 \mathrm{~m}$.

A Sea-Bird SBE16plusV2 CTD, equipped with a SBE43 oxygen sensor, was moored in $27 \mathrm{~m}$ of water depth at the NW corner of the VPS array, to record conductivity, temperature, depth, and dissolved oxygen (Fig. 1; Sea-Bird Electronics, Bellevue, WA, USA). The CTD was positioned $1 \mathrm{~m}$ off bottom and sampled once every 60 min, during the summer months. The CTD was downloaded and serviced approximately bimonthly and was removed for winter.

Ocean conditions in Oregon during winter months (October-March) are typified by large, energetic storms that generate considerable acoustic noise. This noise greatly increases tag detection interference, particularly in shallow water. Thus, for the winter array, we removed all co-located synctags to increase the detection probability of fish tags. This low-resolution winter array had 9 receivers spaced $350 \mathrm{~m}$ apart covering an acoustic detection area of approximately $2.08 \mathrm{~km}^{2}$ to acquire presence/absence-only data for fish within the reef area (Fig. 1). All acoustic receivers for both arrays (summer and winter) were downloaded and serviced bimonthly on average.

The acoustic receivers for the VPS grid and perimeter fence were deployed on 5/10/16 and 5/11/16, and the Sea-Bird SBE16plus V2 was deployed on 5/17/16 (Fig. 1). These instruments were removed on $9 / 30 / 16$ and replaced with the simple 9-receiver presence/absence winter array (Fig. 1). The winter array was downloaded on 11/16/16, 1/29/17 and removed on 4/18/17. Both winter and summer arrays performed well, providing good coverage throughout the 11-month period. One receiver in the summer VPS grid failed to download on 5/31/16 and was replaced and one receiver was found missing upon the final pull of the winter grid.

Acoustic tags and fish handling

Fish were tagged with V13AP coded acoustic transmitters $(69 \mathrm{kHz}, 153 \mathrm{~dB}, 13 \times 42 \mathrm{~mm}$, pressure sensing to $136 \mathrm{~m}$ ) which transmit a unique tag ID to the receiver. The tags also transmit the tags depth (m) and acceleration rate $\left(\mathrm{m} \mathrm{s}^{-2}\right)$ which is used as a measure of activity (VEMCO, Nova Scotia, Canada). To maximize detections, we chose to use the larger V13 tag (weight $=6.5 \mathrm{~g}$ in water) which provided long battery life (365 days) at a high sampling rate (random delay 60-180 s); therefore, we elected to tag larger fish (fork length $>32 \mathrm{~cm}$ ) to reduce the effect of tag weight.

Due to concerns with species identification of this cryptic species, Oregon Department of Fish and Wildlife Marine Fisheries Research staff were trained with known samples to visually differentiate between Deacon and Blue Rockfish. Further, species identification of tagged fish was visually confirmed by Dr. Wolfe Wagman, coauthor of the Deacon Rockfish Frable et al. (2015) species description.

Deacon Rockfish can suffer fatal injuries from barotrauma when captured from depths $>28 \mathrm{~m}$ (Hannah et al. 2008; Hannah et al. 2012). Further, imprudent surface handling results in reduced submergence success of released fish (Hannah et al. 2008). To mitigate these effects, the following techniques were used to capture and handle fish chosen for tagging:

1. To compensate for the weight of the acoustic tag, we selected fish $>32 \mathrm{~cm}$ total length which, for Deacon Rockfish, only include sexually mature females (Hannah et al. 2015).

2. Fish were captured using hook and line gear with small terminal tackle (Sabiki rigs), in water depths less than 26 m. Following Rankin et al. (2016), fish were immediately recompressed in drum-type cages and held at depth for $24 \mathrm{~h}$ to ensure survival and to resolve barotrauma before tagging. Studies have shown that many rockfish species, including Deacon Rockfish, do not experience barotrauma a second time upon returning to the surface within 24 $48 \mathrm{~h}$ of initial recompression. Therefore, they can be handled at surface pressure during that time without further gas expansion injury (Hannah et al. 2012; Rankin et al. 2016). 
3. Fish were tagged externally as per Hannah and Rankin 2011, in order to decrease surgical trauma and to increase tag detection in the array (Dance et al. 2016).

4. Fish were released into a floating bottomless sea pen after tagging, to descend under their own power (Hannah et al. 2008).

Data analysis

\section{Oceanographic data}

To examine how fish behavior changed during periods of hypoxia and normoxia, we used our CTD to identify periods of normoxia and periods hypoxia. Dissolved oxygen (DO) levels are strongly influenced by water temperature. Therefore, we minimized temperature as a confounding factor by identifying and selecting time periods of hypoxia and normoxia with similar temperature ranges and means. Following Diaz and Rosenberg (1995), the hypoxic period was defined by a mean dissolved oxygen $<2 \mathrm{mg}^{-1}$ and the normoxia period by a mean dissolved oxygen $\geq 2 \mathrm{mg} \mathrm{l}^{-1}$. Differences in oxygen and temperature during these two time periods were compared using a Welch's two sample $t$ test. Based on examination of the CTDs dissolved oxygen data, we designated two 11-day time periods: one normoxia period and one hypoxia period. These periods definitions were used to subset the acoustic telemetry data to be used in a focused analysis of how home range, site fidelity, activity, and depths differed between hypoxia and normoxia periods.

\section{Residency and habitat usage}

Acoustic tag transmissions from tagged semi-pelagic fishes (such as Deacon Rockfish) are highly detectable, generating hundreds of validated detections per day in most conditions. However, during high ambient noise events, such as high wind and swell generated by storms, detection rates are reduced; therefore, we used a minimum of six validated detections per day to establish residence. Six validated detections allowed us to determine whether a tag was on the sea floor or on a live fish, as indicated by variation in transmitted depth and/ or activity level. Residence time was defined as the number of days live fish (active tags) were detected during the 11-month study period.
We first examined how the core area and home range differed between tagged fish. Spatial analyses were only conducted during summer months when we had highresolution position data from the VPS array (May-September). Position data used for home range and space utilization analyses was filtered for $<21 \mathrm{~m}$ HPE (horizontal position error), defined as "a relative, unitless estimate of how sensitive a calculated position is to errors in its inputs", and is the estimated precision of the system for this array and the conditions (VEMCO, Nova Scotia, Canada). Initial analyses filtering HPE data to values as low as $3 \mathrm{~m}$ demonstrated that the only effect on our data was to reduce our sample sizes and therefore we elected to only filter data to a value of $21 \mathrm{~m}$. We estimated the home range and core areas for each tagged fish residing within the array, where home range was defined as the $95 \%$ kernel density estimator (KDE) and the core area was defined as the 50\% KDE. KDEs were calculated using the program Geospatial Modeling Environment (GME, version 0.7.4.0) implemented in R (Beyer 2015; R Core Team 2018). Areas were estimated using the tool "isopleths" $\mathrm{c}(0.95,0.5)$ in GME.

We next examined how home ranges and core areas differed between daytime and nighttime. Daytime and nighttime were defined as daily 5 -h periods in the middle of the day or night. These time periods were chosen to remove potential crepuscular or transition behaviors from the analyses. For analysis of both the home range and core area data, we estimated a maximum distance from the calculated center of the core area using "genpointinpoly" in GME. We also examined the foray behavior of each fish in their core area and home range. Forays were defined as a series of movements, which were sequential in time and space, at least $100 \mathrm{~m}$ away from the calculated center of activity, and lasting for more than $1 \mathrm{~h}$ (Rankin et al. 2013). Following a similar study, in Rankin et al. 2013, foray distances were calculated from individual detections, and foray duration was estimated based on the time a tagged fish left and returned to a location less than $100 \mathrm{~m}$ from its center of activity. These analyses of home range and core areas were then repeated with telemetry data subset to only include the hypoxia and normoxia periods defined in the "Oceanographic data" section.

To determine if fish utilize habitats of different rugosity during day and night, underlying bathymetric data from high-resolution Digital Elevation Model (DEM) layers were extracted from each tagged fish's 
daytime and nighttime core area position data. Geomorphology analysis was conducted using the Vector Ruggedness Modeling (VRM) tool in the Benthic Terrain Modeler (BTM) implemented in ArcGIS 10.3 (Hobson 1972; Sappington et al. 2007; ESRI 2015). Vector ruggedness provides a metric for how rugose a reef is; specifically, higher values denote more rugose reef. From the underlying DEM raster, a $(2 \mathrm{~m} \times 2 \mathrm{~m}) \mathrm{VRM}$ layer was created using BTM geomorphology tool, and neighborhood size (1) was chosen at the smallest resolution.

\section{Daily and seasonal behavior}

Analysis of within day and seasonal patterns of accelerometer and depth data were conducted using generalized additive mixed effects models (GAMMs) using the mgcv package in R version 3.5.1, Feather Spray (Wood 2004; Wood 2011). Spatial and temporal autocorrelation were tested for using the DHARMa package (Hartig 2020). Only data from resident fish were utilized in these analyses. Data were first explored following the protocols established by Zuur et al. (2010). Four models were developed. Two models (one for activity, one for depth) were developed to assess how fish behavior changed over the course of our entire study, and two models were developed to compare activity and depth during the periods we defined as hypoxic and normoxic. These data for the second set of models are a subset of the larger seasonal dataset but were analyzed separately so as to have an approximately equal number of observations for each category of oxygen level (see the "Oceanographic data" section).

For both sets of models, fish activity was log transformed to reduce spread and allow models to be developed using a normal distribution. Depth did not require a transformation and was modeled using a normal distribution. For all models, all observations recorded by the receivers were included, in other words potentially up to 1440 observations per fish per day. However, the randomized ping rates of the tags and the high potential for every ping to not be received by a receiver reduced the number of daily observations per tag. For the first set of models (comparing activity and depth over the duration of the study), the variables included in the model were hour of the day (continuous), and month of the year (categorical). An interaction between hour of the day and month of the year was also examined. For the second set of models (comparing activity and behavior during hypoxic and normoxic periods), the variables included in the model were (1) hour of the day (continuous) and (2) oxygen level (categorical). An interaction between hour of the day and oxygen level was also examined.

In both sets of models, continuous variables were modeled using a cyclic cubic regression spline to account for the cyclic nature of hour of the day. A cyclic cubic regression spline requires that the best fit line start and stop at the same point on the y-axis. With hour of the day, this is important because a large behavioral shift from, for example, 23:59 to 00:01, is ecologically unrealistic. Regardless of model, we included the tag ID of each individual fish as a random effect in the model to account for intra-tag variability (Pinheiro and Bates 2000). We also included a first-order autoregressive correlation structure (AR1) to account for temporal autocorrelation between successive observations (Zuur et al. 2009). No evidence of spatial autocorrelation was found. Model selection was conducted by comparing Akaike Information Criterion (AIC) values for all possible model formulations (Burnham and Anderson 2004). The model structure with the lowest AIC value was deemed the best-fit model.

\section{Results}

\section{Oceanography}

Periodic multiday hypoxic conditions were detected in the Seal Rocks array throughout the summer season (Fig. 2). The dates assigned for the 11-day comparison periods were: (a) hypoxia; July $20-30$ (DO range $0.63-$ $2.40 \mathrm{mg} \mathrm{l}^{-1}$, mean DO $=1.4 \mathrm{mg} \mathrm{l}^{-1}$, mean $\mathrm{T}=7.91^{\circ} \mathrm{C}$ ), (b) normoxia; August 16-26 (DO range 2.43$5.60 \mathrm{mg} \mathrm{l}^{-1}$, mean $\mathrm{DO}=3.19 \mathrm{mg} \mathrm{l}^{-1}$, mean $\mathrm{T}=$ $7.90{ }^{\circ} \mathrm{C}$ ). (Fig. 2). Oxygen levels during hypoxia and normoxia differed significantly from one another $(t(478)=-40.14, p<0.001)$. Temperature was also significantly different during the two periods $(t(478)=$ $3.58, p<0.001)$. However, the mean temperature difference between the two time periods was only $0.01{ }^{\circ} \mathrm{C}$, indicating conditions were highly static.

Fish

Eleven female Deacon Rockfish were tagged on 5/17/ 2016. Fish ranged from 33 to $41 \mathrm{~cm}$ total length. Based 


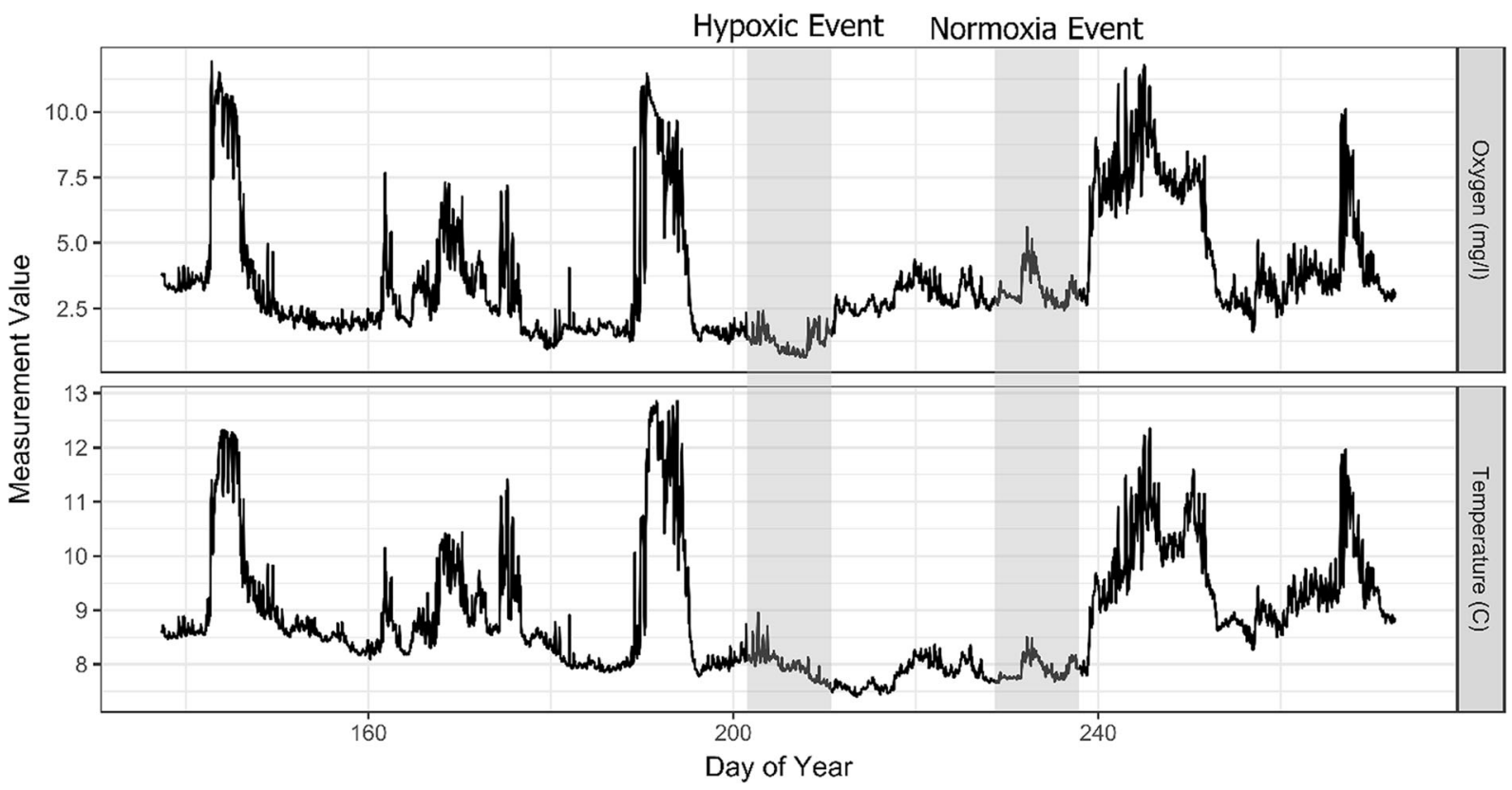

Fig. 2 Mean daily dissolved oxygen and temperature for the Seal Rocks study area from 5/17/16 through 9/30/16. Two 11-day comparison periods are indicated by gray shading: Hypoxia (DO range $0.63-2.40 \mathrm{mg} \mathrm{l}^{-1}$, mean $\mathrm{DO}=1.4 \mathrm{mg} \mathrm{l}^{-1}$, mean $\mathrm{T}=7.91^{\circ} \mathrm{C}$ ) from 7/20/16-7/30/16; Normoxia (DO range 2.43-5.60 $\mathrm{mg}^{-1}$, mean $\mathrm{DO}=3.19 \mathrm{mg}^{-1}$, mean $\mathrm{T}=7.90^{\circ} \mathrm{C}$ ) from $8 / 16 / 16-8 / 26 / 16$.

on length weight relationships, the tag weighed from $0.62-1.19 \%$ of fish body weight (unpublished data). Prior to release, tagged fish were alert, active, free of barotrauma signs, and were able to descend without assistance (Table 1).

\section{Residency and habitat usage}

After release, all 11 fish returned to the location of capture within $27 \mathrm{~h}$ (home foray, Table 1). One fish was detected in the grid for 112 days, before showing evidence of predation. Four fish had residence times between 13 and 37 days before leaving the array; two were located within the fence area, but were inactive, indicating tag loss, predation, or mortality. The other two fish were detected leaving the perimeter area via the north fence, and designated as "traveler" (Table 1, Fig. 1). Six fish "residents" remained in the grid and were consistently detected for 246-326 days (Table 1).

The 19 weeks of high-resolution VPS data showed the six resident fish had high site fidelity and small home ranges ranging in area from 3511 to $6875 \mathrm{~m}^{2}$ (mean 95\% KDE $=4907 \mathrm{~m}^{2}$; Table 2, Fig. 3). These home ranges correspond to circles with a radius of
Oxygen levels during hypoxia and normoxia differed significantly from one another $(t(478)=-40.14, p<0.001)$. Temperature was also significantly different during the two periods $(t(478)=3.58$, $p<0.001$ ); however, the mean temperature difference between the two time periods was only $0.01{ }^{\circ} \mathrm{C}$, indicating conditions were highly static

approximately $33-47 \mathrm{~m}$. Core areas ranged from 324 to $756 \mathrm{~m}^{2}$ (mean $50 \% \mathrm{KDE}=477 \mathrm{~m}^{2}$; Table 2, Fig. 3). These core areas correspond to circles with a radius of approximately 10-16 $\mathrm{m}$. Mean nighttime home range and core area size were 50 and $25 \%$ smaller than daytime home range and core area size, respectively (Table 2, Fig. 3). With the exception of fish TD03, which was undetected after day 246, five resident fish continued to be active and detected in the winter grid for 306-323 days (Table 1). Four resident fish (TD04, TD06, TD09, and TD10) consistently utilized an overlapping home range area (Fig. 3).

All six resident fish showed a substantial change in behavior during the hypoxic period, resulting in both larger and smaller core areas used. Foray behavior was exhibited by all six resident fish during the hypoxia period only. Forays ranged in duration from 23 to $88 \mathrm{~h}$ and from 923 to $2985 \mathrm{~m}$ traveled (Table 2, Fig. 4). The farthest distance from the calculated center of the core was $807 \mathrm{~m}$ for TD02 (Table 2, Fig. 4).

Resident fish used more rugose habitat during daytime period than at night, although the differences were much lower for fish TD03 than for other fish (Fig. 5). Further, fish utilized significantly more rugose habitat 
Table 1 Summary information and status of 11 tagged Deacon Rockfish. Fish status indicates area of final detection and classification of fish: fence (detected on fence), inactive (tag inactive), resident (in VPS array), and traveler (moved beyond fence). Residence time was defined as the number of days live fish (active tags) were detected during the 11-month study period. Home foray is the distance between the position of release of tagged fish to a location less than $100 \mathrm{~m}$ from the calculated center of activity. Home foray duration is the time elapsed between the time of release of a tagged fish to a location $<100 \mathrm{~m}$ from the calculated center of activity

\begin{tabular}{|c|c|c|c|c|c|c|}
\hline Fish ID & Total length $(\mathrm{cm})$ & $\begin{array}{l}\text { Residence } \\
\text { time (day) }\end{array}$ & $\begin{array}{l}\text { Home foray } \\
\text { distance }(\mathrm{m})\end{array}$ & $\begin{array}{l}\text { Home foray } \\
\text { duration (hh:mm) }\end{array}$ & Status & $\begin{array}{l}\text { Predation/mortality * } \\
\text { Departure** (date) }^{*}\end{array}$ \\
\hline TD01 & 33 & 13 & 1896 & $2: 36$ & Fence/inactive & $05 / 31 / 2016^{*}$ \\
\hline TD02 & 35 & 323 & 581 & $14: 58$ & Resident & \\
\hline TD03 & 33 & 246 & 556 & $18: 35$ & Resident/traveler & $01 / 18 / 2017 * *$ \\
\hline TD04 & 34 & 312 & 659 & $10: 22$ & Resident & \\
\hline TD05 & 41 & 27 & 1598 & $16: 11$ & Traveler & $06 / 14 / 2016^{* *}$ \\
\hline TD06 & 35 & 306 & 311 & $26: 46$ & Resident & \\
\hline TD07 & 36 & 37 & 341 & $11: 20$ & Fence/inactive & 07/06/2016* \\
\hline TD08 & 39 & 35 & 382 & $21: 00$ & Traveler & $06 / 20 / 2016^{* *}$ \\
\hline TD09 & 39 & 326 & 311 & $22: 09$ & Resident & \\
\hline TD10 & 40 & 322 & 404 & 8:00 & Resident & \\
\hline TD11 & 33 & 112 & 589 & $21: 44$ & Resident/inactive & 07/08/2016* \\
\hline
\end{tabular}

during the day, night, or in total as compared to the average habitat rugosity for the area encompassed by the array (Fig. 5).

Daily and seasonal behavior

The best-fit models for both activity and depth included all variables and their interaction plus the addition of the random effect of fish tag (Table 3). For activity, the model explained $21.8 \%$ of the variability in the data, and for depth, the model explained 58\% of the variability in the data (Table S1). During the summer months of May-September, resident fish showed a trend of higher diurnal activity for $8-12 \mathrm{~h}$ a day in shallower depths versus lower activity levels in deeper waters at night (Table 3, Figs. 6 and 7). This day/night trend became less evident in October, and was not evident from November through March, during which time there were no major differences in average activity level or depth readings between day and night (Figs. 6 and 7).

Table 2 Home range, core activity area, and foray summaries for resident Deacon Rockfish. Home range is the 95\% Kernel Density Estimator (KDE) and core area is the $50 \% \mathrm{KDE}$. Forays were

defined as a series of movements, which were sequential in time and space, at least $100 \mathrm{~m}$ away from the calculated center of activity, and lasting for more than $1 \mathrm{~h}$ (Rankin et al. 2013)

\begin{tabular}{|c|c|c|c|c|c|c|c|c|c|c|c|c|c|}
\hline \multirow{2}{*}{$\begin{array}{l}\text { Resident } \\
\text { fish ID }\end{array}$} & \multicolumn{6}{|c|}{ Home range/core area/day/night } & \multicolumn{2}{|c|}{ Normoxia } & \multicolumn{2}{|c|}{ Нypoxia } & \multicolumn{3}{|c|}{ Hypoxia foray } \\
\hline & $\begin{array}{l}\text { Home } \\
\text { range } \\
\left(\mathrm{m}^{2}\right)\end{array}$ & $\begin{array}{l}\text { Core } \\
\text { area } \\
\left(\mathrm{m}^{2}\right)\end{array}$ & $\begin{array}{l}\text { Home } \\
\text { range } \\
\text { day }\left(\mathrm{m}^{2}\right)\end{array}$ & $\begin{array}{l}\text { Core } \\
\text { area } \\
\text { day } \\
\left(\mathrm{m}^{2}\right)\end{array}$ & $\begin{array}{l}\text { Home } \\
\text { range } \\
\text { night } \\
\left(\mathrm{m}^{2}\right)\end{array}$ & $\begin{array}{l}\text { Core } \\
\text { area } \\
\text { night } \\
\left(\mathrm{m}^{2}\right)\end{array}$ & $\begin{array}{l}\text { Home } \\
\text { range } \\
\left(\mathrm{m}^{2}\right)\end{array}$ & $\begin{array}{l}\text { Core } \\
\text { area } \\
\left(\mathrm{m}^{2}\right)\end{array}$ & $\begin{array}{l}\text { Home } \\
\text { range } \\
\left(\mathrm{m}^{2}\right)\end{array}$ & $\begin{array}{l}\text { Core } \\
\text { area } \\
\left(\mathrm{m}^{2}\right)\end{array}$ & $\begin{array}{l}\text { Foray } \\
\text { distance } \\
(\mathrm{m})\end{array}$ & $\begin{array}{l}\text { Distance } \\
\text { from } \\
\text { center }(\mathrm{m})\end{array}$ & $\begin{array}{l}\text { Duration } \\
\text { (hh:mm) }\end{array}$ \\
\hline TD02 & 3715 & 324 & 3692 & 499 & 1949 & 162 & 3487 & 531 & 11,171 & 1339 & 1726 & 807 & $27: 37$ \\
\hline TD03 & 6530 & 480 & 7122 & 810 & 3087 & 112 & 5125 & 962 & 10,928 & 1328 & 923 & 299 & $87: 48$ \\
\hline TD04 & 4546 & 352 & 4762 & 473 & 870 & 67 & 5392 & 610 & 6860 & 714 & 1081 & 425 & $55: 25$ \\
\hline TD06 & 3511 & 427 & 2922 & 373 & 1282 & 95 & 5016 & 868 & 3480 & 368 & 981 & 135 & $57: 26$ \\
\hline TD09 & 4264 & 526 & 3550 & 374 & 5551 & 290 & 4830 & 974 & 6852 & 260 & 2985 & 312 & $29: 10$ \\
\hline TD10 & 6875 & 756 & 6945 & 875 & 1862 & 123 & 8597 & 1460 & 3682 & 367 & 1246 & 253 & $23: 04$ \\
\hline Mean & 4907 & 477 & 4832 & 567 & 2434 & 141 & 5408 & 901 & 7162 & 729 & 1490 & 372 & $46: 45$ \\
\hline
\end{tabular}



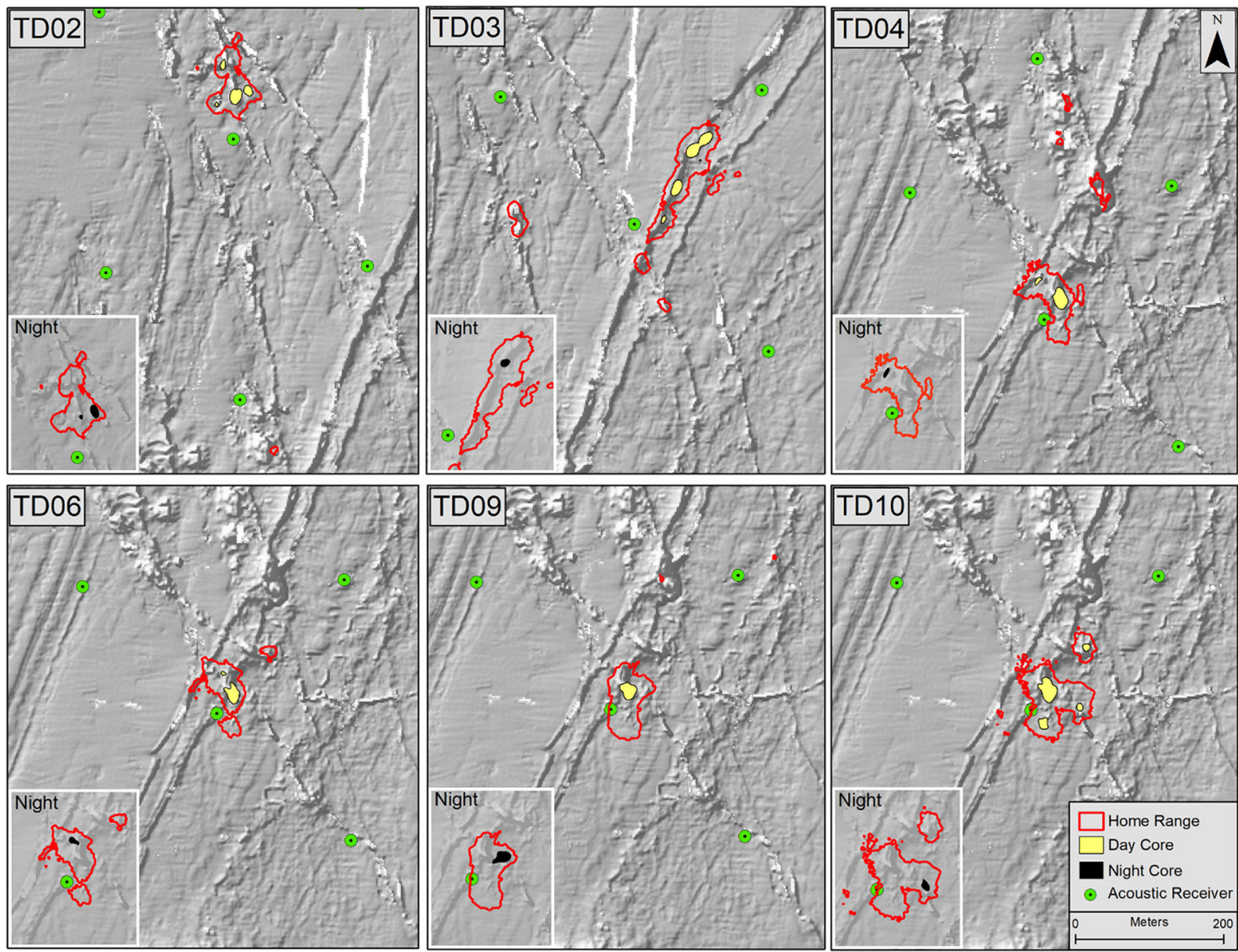

Fig. 3 Comparison of home range, daytime and nighttime core areas for resident Deacon Rockfish. Areas are within the VPS array and overlay multibeam bathymetry. Date range 5/19/16 through 9/30/16. Main panels: Home Range Area (KDE 95\%, red outline) and Daytime Core Activity Area (KDE 50\%, yellow fill). Inset panels are of the home range area, at the same scale for Nighttime Core Activity Area (KDE 50\%, black fill). Fish inhabit different and smaller core areas during the nighttime, than in the daytime. Four fish had overlapping home ranges (TD04, TD06, TD09, TD10)
The best-fit models describing how both activity and depth varied between hypoxic and normoxic events included all variables and their interactions (Table 3). For activity, the model explained $27.2 \%$ of the variability in the data (Table S2). For depth, the model explained $36.3 \%$ of the variability in the data (Table S2). During normoxia, fish increased activity and moved to shallower depths during sunrise hours and decreased activity and descended to deeper depths at sunset (Fig. 8). This was in contrast to hypoxia conditions during which activity levels remained relatively stable, and changes in occupied depth over the course of the day were drastically reduced (Fig. 8).

\section{Discussion}

Overall, in our study, there is strong evidence of site residency for female Deacon Rockfish. The resident Deacon Rockfish displayed high site fidelity having relatively small core areas during the day, and even smaller core areas during the night. Activity and location in the water column displayed a strong diel cycle that shifted seasonally with more static activity levels and depth usage during winter months. Hypoxic events altered daily behavior and depth occupancy as well as the way in which fish utilized the reef. Although we found strong evidence of residency, the three travelers detected leaving the array may indicate response to an 


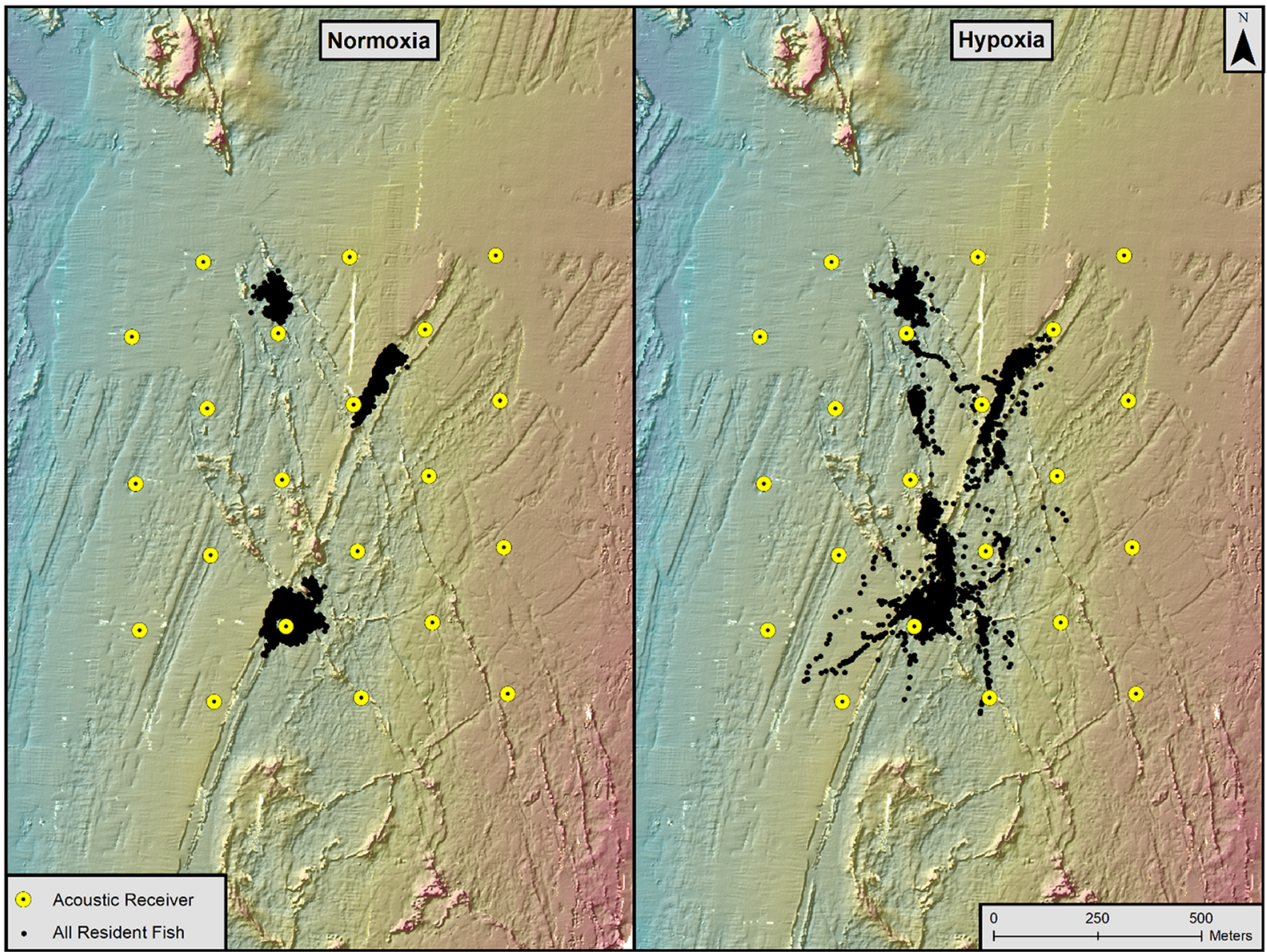

Fig. 4 Combined resident fish positions in VPS array area for two comparison periods: Normoxia and Hypoxia. Data included both daytime and nighttime for the two 11-day periods. Forays away from the core center were only observed during the hypoxic period

environmental cue, a shift in core area beyond the scope of the array, and/or emigration from the nearshore reef area.

High long-term survival and consistently high detection of resident fish during our 11-month study indicate that some Deacon Rockfish do not exhibit a seasonal migration away from nearshore reefs. This finding is supported by a concurrent study where researchers were able to collect Deacon Rockfish using hook and line gear, with small terminal tackle, throughout a 12-month period (Vaux et al. 2019). Further, underwater video observations in these areas routinely observed Deacon Rockfish during summer months (Rasmuson et al. 2020). In short, our work, in combination with other studies, indicates that at least a component of Deacon Rockfish do not likely undergo a seasonal migration away from nearshore reefs. However, since our study was restricted to large female Deacon Rockfish, we cannot exclude the hypothesis of an ontogenetic migration or a seasonal migration only exhibited by male rockfish or smaller females. Multiple behavior modes have been observed in the Australasian snapper (Pagurus auratus) and we cannot discount that possibility here (Egli and Babcock 2004). That said, in the nearshore, Vaux et al. (2019) observed both male and female Deacon Rockfish in all size classes, throughout the year, suggesting that at least a component of the smaller males and females remain in the nearshore. Thus, if there are different behavioral modes, it is more likely a behavioral syndrome as opposed to a sex or length based trait (Bell and Sih 2007).

Given that Deacon Rockfish appear to remain in the nearshore throughout the year, why does the recreational fishing fleet not capture them during summer months? We hypothesize the diet of Deacon Rockfish may be the answer to this question. Food items ingested by Deacon 
TD02

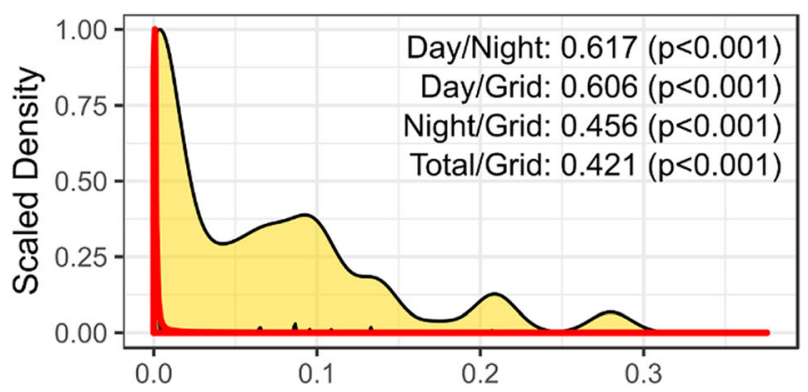

TD04

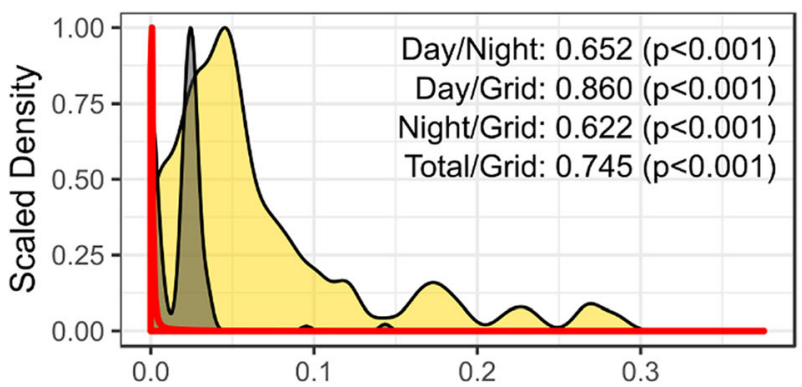

TD09

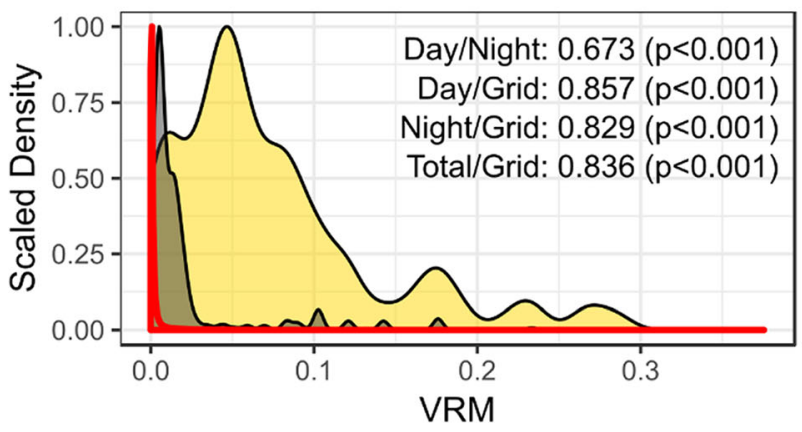

Fig. 5 Vector Ruggedness Measure (VRM) comparing resident Deacon Rockfish area usage to the VPS array area. Resident Deacon Rockfish daytime VRM (yellow), nighttime VRM (gray), and the entire VPS acoustic array area (red). Text denotes results of Kolmogorov-Smirnov tests comparing Deacon Rockfish usage between time periods and to the grid VRM values. Day-Daytime

Rockfish in Vaux et al. 2019 included gelatinous zooplankton and small planktonic crustaceans: the colonial tunicate Pyrosoma atlanticum, hydrozoan Velella vellela, ctenophore Pleurobrachia bachei, brachyuran zoeae/megalopae, and pelagic amphipods. Feeding on gelatinous zooplankton requires specific visual abilities which allow some species of Rockfish (e.g., Blue Rockfish) to see and feed upon very small and/or transparent prey items (Hobson and Chess 1988; Hobson et al. 1996). In the closely related planktivorous Blue
TD03

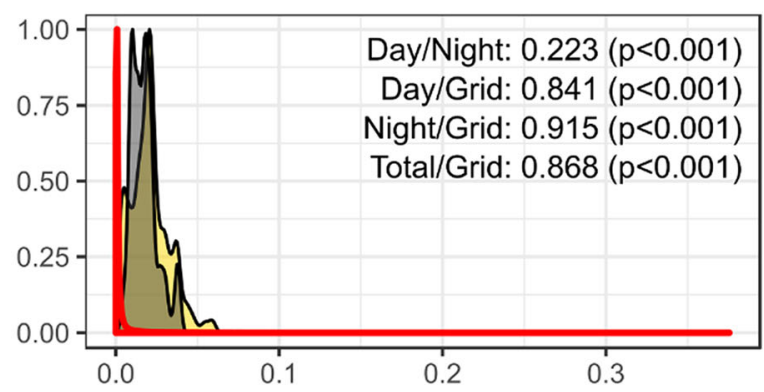

TD06

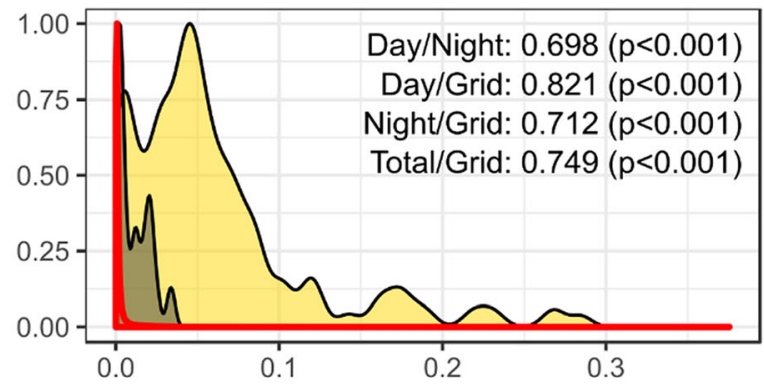

TD10

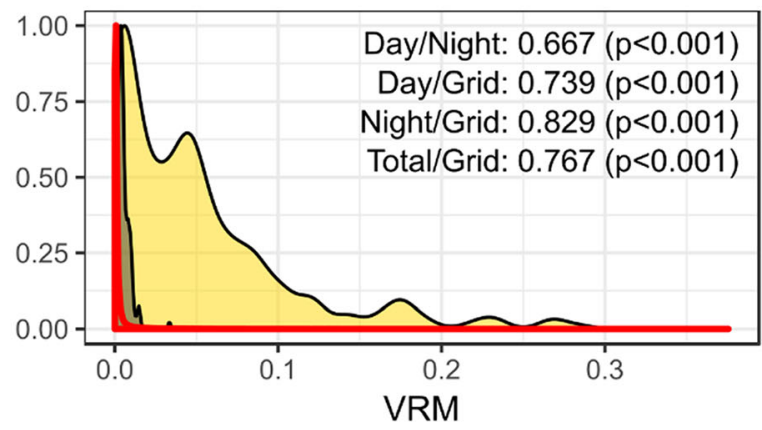

usage, Night- Nighttime usage, VRM metric for the VPS array, Total-Usage of the tag during day and night combined. Most resident fish used more rugose habitat during the daytime period than during the nighttime period. All resident fish used more rugose habitat during the day, night, or in total compared to the average habitat rugosity for the area encompassed by the array

Rockfish, electroretinograms demonstrated that Blue Rockfish had low sensitivity to lower light levels than more nocturnally active rockfish (Reilly and Thompson 2007). Thus, the cryptic Blue and Deacon Rockfish may have similar unique visual capabilities making them well adapted to daytime light levels and to feeding on small, clear planktonic prey (Green et al. 2014). Accordingly, we hypothesize that Deacon Rockfish may be resistant to standard fishing techniques because recreational terminal gear typically does not mimic the 
Table 3 Summary of model selection for fish acceleration (proxy for activity level) and depth occupied. Model selection for activity level (left) and depth occupied (right) includes the entire year's dataset (upper) and the shorter dataset comparing oxygen level (lower)

\begin{tabular}{|c|c|c|}
\hline \multicolumn{3}{|l|}{ A) Seasonal model } \\
\hline Model structure & $\begin{array}{l}\text { Acceleration: } n=190,595 \\
\Delta \text { AIC }\end{array}$ & $\begin{array}{l}\text { Depth: } n=380,889 \\
\Delta \text { AIC }\end{array}$ \\
\hline s(Hr x Month)+Month + re(Fish) & $\mathbf{0}$ & 0 \\
\hline $\mathrm{s}(\mathrm{Hr} \times \mathrm{Month})+$ Month & 1156 & 274,935 \\
\hline $\mathrm{s}(\mathrm{Hr})+$ Month+re(Fish) & 11,894 & 19,545 \\
\hline $\mathrm{s}(\mathrm{Hr})+$ Month & 13,085 & 287,202 \\
\hline $\mathrm{s}(\mathrm{Hr} \times \mathrm{Month})+\mathrm{re}(\mathrm{Fish})$ & 17,320 & 64,143 \\
\hline s(Hr x Month) & 19,524 & 313,897 \\
\hline $\mathrm{s}(\mathrm{Hr})+\mathrm{re}(\mathrm{Fish})$ & 31,763 & 82,271 \\
\hline $\mathrm{s}(\mathrm{Hr})$ & 33,844 & 326,280 \\
\hline Month+re(Fish) & 23,783 & 33,659 \\
\hline Month & 25,103 & 291,683 \\
\hline re(Fish) & 44,461 & 94,205 \\
\hline 1 & 46,721 & 330,311 \\
\hline \multicolumn{3}{|l|}{ B) Hypoxia and normoxia model } \\
\hline Model structure & $\begin{array}{l}\text { Acceleration: } n=11,097 \\
\Delta \text { AIC }\end{array}$ & $\begin{array}{l}\text { Depth: } n=22,299 \\
\Delta \text { AIC }\end{array}$ \\
\hline s(Hr x Oxygen) + Oxygen + re(Fish) & $\mathbf{0}$ & $\mathbf{0}$ \\
\hline $\mathrm{s}(\mathrm{Hr}$ x Oxygen $)+$ Oxygen & 980 & 4588 \\
\hline $\mathrm{s}(\mathrm{Hr})+$ Oxygen+re(Fish) & 519 & 1671 \\
\hline $\mathrm{s}(\mathrm{Hr})+$ Oxygen & 1688 & 6135 \\
\hline $\mathrm{s}(\mathrm{Hr} x$ Oxygen $)+\mathrm{re}($ Fish $)$ & 2303 & 1297 \\
\hline $\mathrm{s}(\mathrm{Hr} x$ Oxygen $)$ & 570 & 6318 \\
\hline $\mathrm{s}(\mathrm{Hr})+\mathrm{re}(\mathrm{Fish})$ & 1688 & 2560 \\
\hline $\mathrm{s}(\mathrm{Hr})$ & 1057 & 7424 \\
\hline Oxygen+re(Fish) & 2303 & 5915 \\
\hline Oxygen & 1774 & 9348 \\
\hline re(Fish) & 2495 & 5296 \\
\hline 1 & 3473 & 10,006 \\
\hline
\end{tabular}

Bold denotes the most parsimonious model

$s$ variable was modeled as a cyclic spline, $r e$ variable modeled as a random effect, $H r$ hour of the day, Month month of the year, Oxygen Categorical definition of oxygen concentration, Fish fish tag ID

preferred summer prey of Deacon Rockfish. These results suggest that periods of relatively low catch of Deacon Rockfish in the recreational fishery may not be indicative of a small population size, but rather a seasonal shift in diet and/or behavior. Furthermore, this dietary shift may provide some resistance to overfishing (under current effort levels), for which the high site fidelity and small home ranges of Deacon Rockfish might otherwise make them vulnerable (Patrick et al. 2010).
Although methods for calculating home range vary between studies, mean home ranges were considerably smaller for resident Deacon Rockfish $\left(0.0049 \mathrm{~km}^{2}\right)$ than other semi-pelagic species like Blue Rockfish in kelp habitat off Central California $\left(0.23 \mathrm{~km}^{2}\right)$ (Green et al. 2014), and Black Rockfish inhabiting the same reef complex in Oregon $\left(0.55 \mathrm{~km}^{2}\right)$ (Parker et al. 2007). Deacon Rockfish utilized small, consistent core areas with mean nighttime core areas being approximately $75 \%$ smaller than the daytime core area. Additionally, 

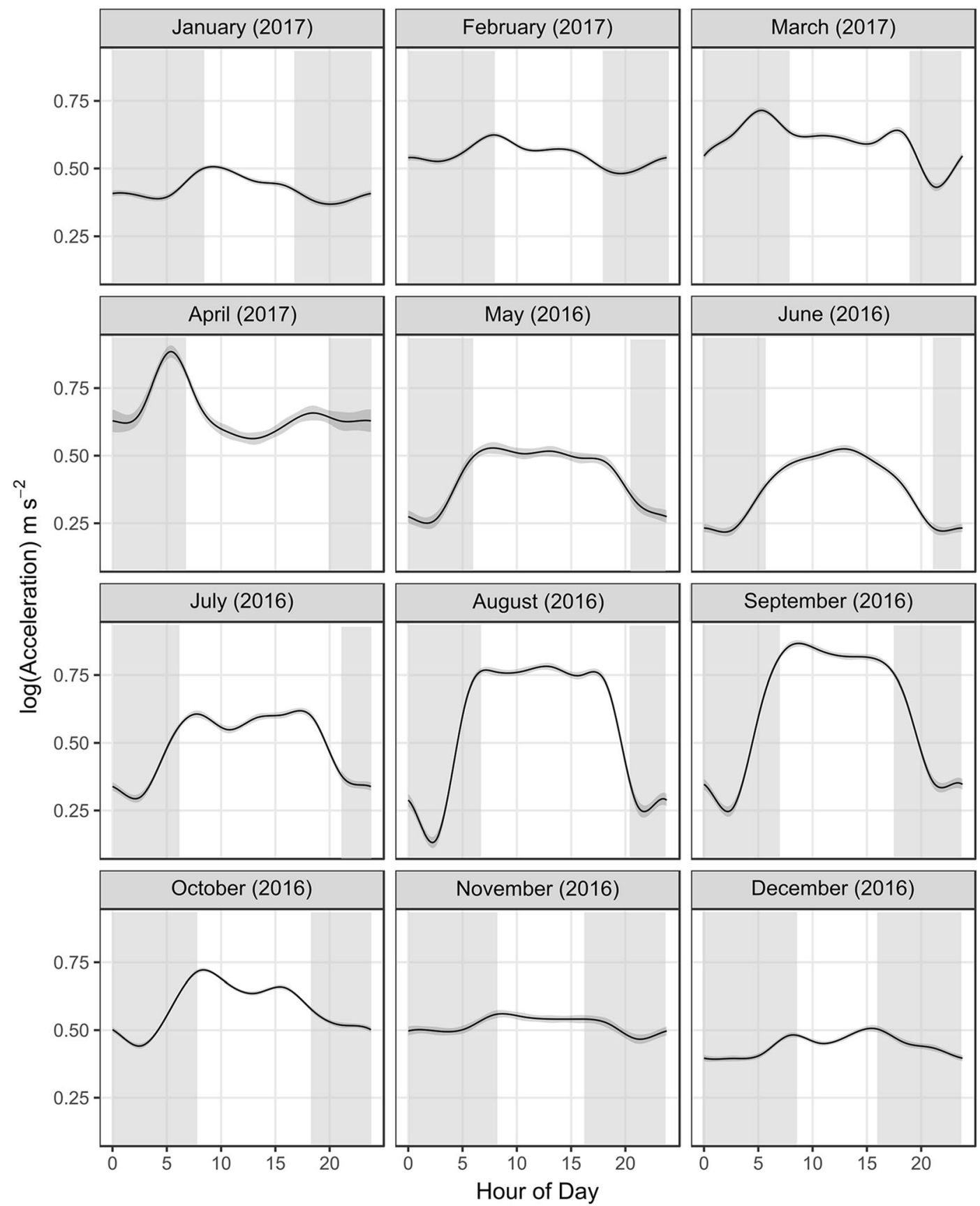

Fig. 6 Relative effect of month of the year on daily activity level of resident Deacon Rockfish. The black line within the gray shading $(95 \% \mathrm{CI})$ is the smoothed response. Vertical gray bars denote the hours after sunset and before sunrise. Fish exhibited a

all fish displayed a distinct behavior trend of switching away from utilizing more rugose habitat during the day, to utilizing less rugose habitat at night. Pairing this observation with the nighttime video surveys where strong diurnal pattern of activity in the summer months, with relatively high levels of activity in the daytime and lower levels during the nighttime

Deacon Rockfish have been observed laying directly on flat bedrock (Rasmuson unpublished data) indicates a shift away from more rugose habitat during the day to a flat bedrock sleeping environment. Why sleep out in 


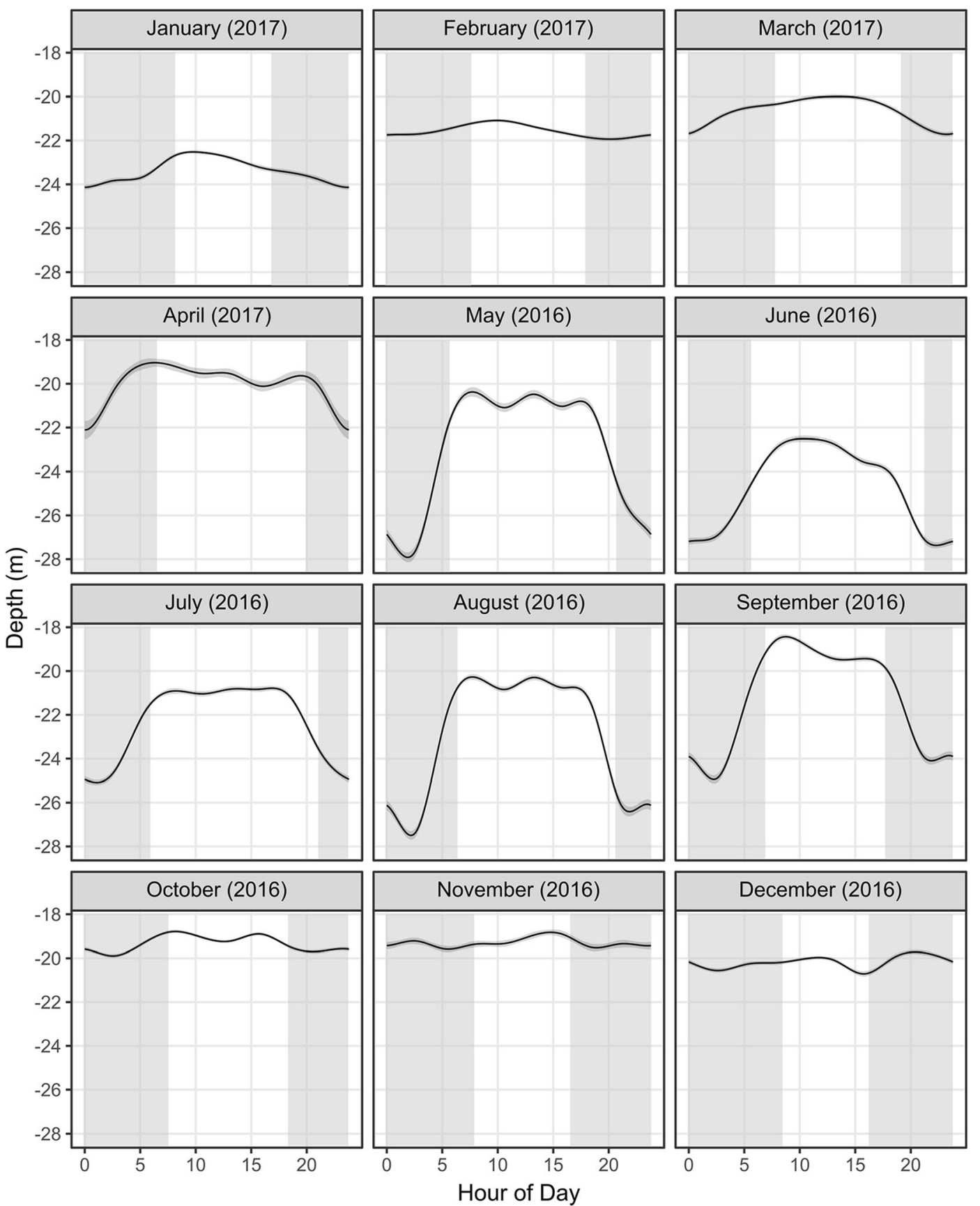

Fig. 7 Relative effect of month of the year on daily depth level occupied by resident Deacon Rockfish. The black line within the gray shading $(95 \% \mathrm{CI})$ is the smoothed response. Vertical gray bars denote the hours after sunset and before sunrise. Fish occupied relatively deeper water depths during the nighttime in the summer months, than in the winter months the open directly on the bottom? In short, we are unsure. At night, Deacon Rockfish adopt much darker coloration so it is possible that laying near or on the bottom provides camouflage from visual predators. However, one would then wonder why lay in the open rather than in cracks like other rockfishes. Alternatively, they may stop their activity at night because as a visual predator of clear planktonic organisms, they may be unable to see 
Fig. 8 Relative effect of oxygen concentration on activity level and depth usage for resident Deacon Rockfish. Activity (log acceleration $\left(\mathrm{m} \mathrm{s}^{-2}\right)$ ) (upper panel) and depth (m) (lower panel) throughout a 24-h day for two 11-day time periods of normoxia and hypoxia. The black line within the gray shading $(95 \% \mathrm{CI})$ is the smoothed response. Vertical gray bars denote the hours after sunset and before sunrise. During normoxia, fish exhibited a diurnal pattern of residing in deeper water during the nighttime with reduced activity. During hypoxia, resident fish remained at shallower depths and exhibited continuous activity with daytime activity lower than normoxic periods and nighttime levels higher than normoxic periods
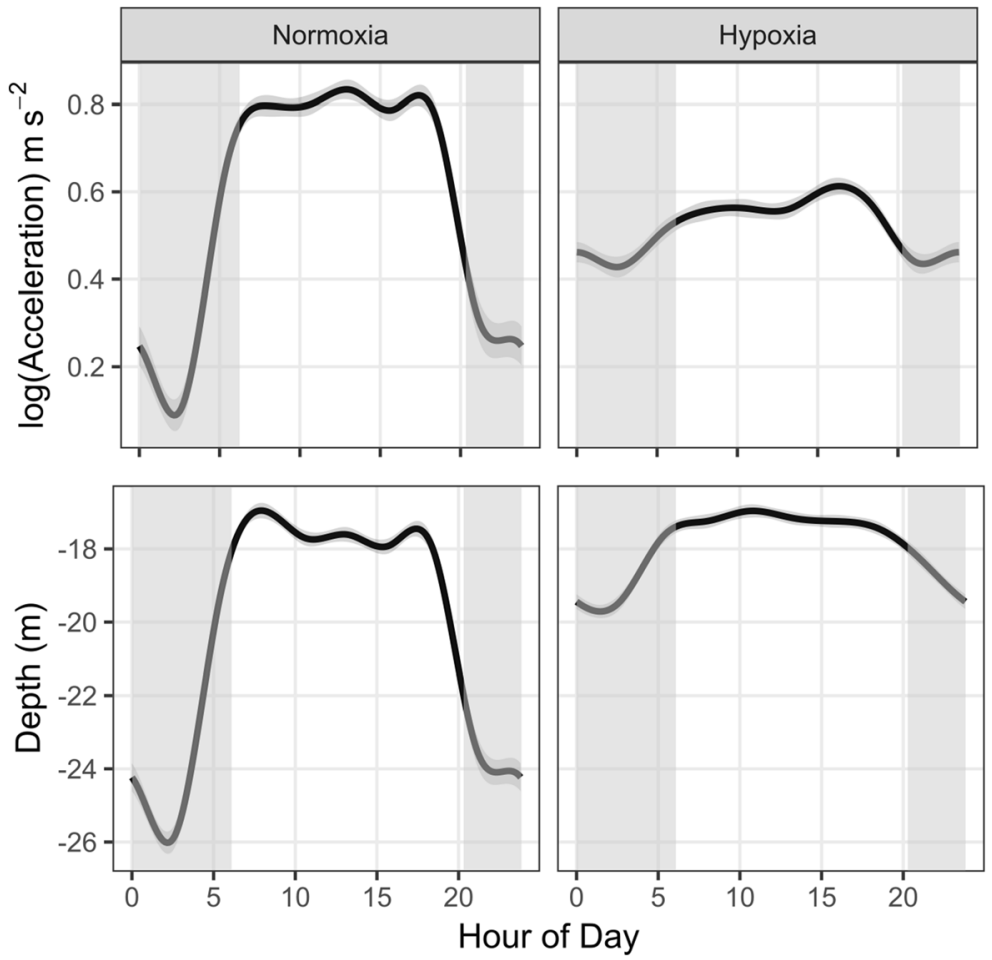

their prey. Ultimately, this remains an open question, which may be answered by further research.

Off Oregon, coastal circulation has two primary periods: the period from the fall transition to the spring transition, hereafter winter, and the period from the spring transition to the fall transition, hereafter summer (Huyer 1979; Strub and James 1988). Characteristically during the summer, conditions alternate between periods of upwelling and downwelling on the continental shelf, though in the nearshore, where this study was conducted, these effects are strongly muted (Austin and Lentz 2002). In the wintertime, the conditions are characteristically downwelling favorable and large storms systematically influence circulation. In 2016, the year our study started, the spring transition occurred on March 27 and the fall transition occurred on September 29, whereas in 2017 the spring transition occurred on April 26 (http://damp.coas.oregonstate. edu/windstress/index.html). It seems likely that the change from heterogeneous acceleration and depth during summer relatively to the more homogenous acceleration and depths of winter is associated with the spring and fall transitions. This likely indicates that the seasonal behaviors we observed are due to prevailing changes in circulation. Unfortunately, the rough winter storms off Oregon during precluded us from leaving our CTD mooring in the water and associating our observed behaviors with abiotic factors.

Tagged fish showed greatly reduced activity in their nighttime core areas, but this pattern was less evident during the wintertime. Some potential hypotheses for this wintertime behavior are that the fish receive less rest during storms because high wave action creates turbulence in nearshore reef areas, or that the fish change to nightly foraging activity during these months. Undoubtedly, other hypotheses exist. The seasonal pattern of high levels of daytime, off-bottom activity, followed by a definitive period of rest observed in the summer months aligns with Green et al. (2014), indicating nocturnal sheltering for Blue Rockfish off Central California. Although Deacon Rockfish had not been established as a separate species at the time of Green's study, the authors confirmed they were already visually differentiating between the two cryptic species and that tagged specimens were all Blue Rockfish (R. Starr, pers comm). The diurnal behavior of Deacon Rockfish is in contrast to Black Rockfish from the Seal Rocks Reef area, which demonstrate mixed diurnal/nocturnal movement patterns (Parker et al. 2008). 
All resident Deacon Rockfish exhibited a response to hypoxic conditions, which interrupted 5 months of otherwise consistent movement patterns. The long-duration forays, well away from core activity areas, were atypical as were the depth and activity patterns for that time of year; fish were moderately active at shallower depths, with no high-level diurnal activity and no nighttime onbottom rest. Our analyses suggest oxygen and temperature differed significantly between the hypoxic and normoxic time periods. However, on average, temperature only differed by $0.01{ }^{\circ} \mathrm{C}$ between the two time periods. Accordingly, although temperature is statistically different between the time periods, we hypothesize that the difference is not ecologically relevant, but rather, the larger difference in oxygen levels between the time periods is a better explanation for the observed behavioral shifts. Deacon Rockfish response to seasonal hypoxia differed considerably from the responses of more benthic rockfish in Oregon. For example, Copper Rockfish reduce their home ranges and activity in response to hypoxia, while Quillback Rockfish showed no change (Rankin et al. 2013).

Hypoxia may also result in increased respiration rate in fish, which is a physiological response to decreased oxygen availability. Movement patterns exhibited by resident fish suggest fish increased their baseline activity to compensate for respiratory stress, and moved beyond their core activity areas towards the surface, to seek areas with higher oxygen levels (Nakanishi and Itazawa 1974; Furse et al. 1996; Kim et al. 1995; Palsson et al. 2008). The independent and irregular forays were likely not prey-seeking behavior, as resident fish maintained a high level of site fidelity, as well as habitat and school fidelity through the rest of the summer season, during which variable upwelling/ downwelling/relaxation patterns intermittently interject pelagic planktonic prey into the system (Hobson and Chess 1988; Checkley Jr and Barth 2009). Additionally unlikely is reproductive activity, which takes place in late summer/fall with parturition in the wintertime (Hannah et al. 2015).

Although our sample size was necessarily small to accommodate the high numbers of synctag detections needed for high-resolution position data, detection numbers and position data for tagged fish was excellent, as mid-water schooling behavior of this semi-pelagic species benefits acoustic transmission. Detection rates can be problematic for more benthic rockfish in high-relief habitat, as habitat can block or distort the acoustic transmission. The high-resolution inner VPS array, combined with the perimeter fence, and fish tags equipped with accelerometer/depth sensors, provided additional certainty about the fate of fish that remained inside or left the array. A larger study in southern Oregon, using similar methods, but tagging both Deacon and Blue Rockfish inhabiting the same area, could shed light on differences in the cryptic pairs' movements in various habitats including un-fished offshore reefs, which may act as refuges for older, more fecund fish found in rockfish conservation areas in Oregon.

Supplementary Information The online version contains supplementary material available at https://doi.org/10.1007/s10641021-01092-w.

Acknowledgments This project would not have been possible without the early support of R.W. Hannah and D.S. Fox. We thank C.D. Good, C.T. Heath, and B.T. Rodomsky for providing fisheries data. R.C. Anderson, G. Krutzikowsky, J.S. Malvitch, and D.W. Wagman provided assistance at sea. We thank D.S. Fox, M. Sommer, and S.D. Groth for an early review of the manuscript. Our sincerest appreciation to Capt. David DeBelloy, and the crew of the CPFV Enterprise, who provided expert logistical support and a superior vessel with which to conduct this work. This research did not receive any specific grant from funding agencies in the public, commercial, or not-for-profit sectors.

Availability of data and material and code Data are available on the Oregon Department of Fish and Wildlife's Natural Resources Information Management Program.

Authors' contributions This manuscript was designed, executed, and written by Leif K. Rasmuson, Matthew T.O. Blume, and Polly S. Rankin. The field investigation was designed and conducted by Blume and Rankin; analysis and writing was by Rasmuson, Blume, and Rankin.

Funding Funding was provided by annually allocated research funding to ODFW's marine fisheries research project.

\section{Declarations}

Ethics approval The Oregon Department of Fish and Wildlife did not have an IACUC (Institutional Animal Care and Use Committee) process in place at the time of the study, one is currently being developed. The collection, handling, and tagging of $S$. diaconus was conducted using the best available science and veterinary practices for minimizing stress and ensuring longevity in captured marine fish, with special emphasis on mitigating the effects of barotrauma. We followed the protocols developed by the American Fisheries Society in Guidelines for the Use of Fishes in Research, which were reviewed and approved by veterinary staff 
of the Oregon Department of Fish and Wildlife, and were found to be consistent with acceptable standards.

Consent to participate and publication All authors participated in this study and consent to its publication.

Conflict of interest The authors declare that they have no conflict of interests.

Open Access This article is licensed under a Creative Commons Attribution 4.0 International License, which permits use, sharing, adaptation, distribution and reproduction in any medium or format, as long as you give appropriate credit to the original author(s) and the source, provide a link to the Creative Commons licence, and indicate if changes were made. The images or other third party material in this article are included in the article's Creative Commons licence, unless indicated otherwise in a credit line to the material. If material is not included in the article's Creative Commons licence and your intended use is not permitted by statutory regulation or exceeds the permitted use, you will need to obtain permission directly from the copyright holder. To view a copy of this licence, visit http://creativecommons.org/licenses/by/4.0/.

\section{References}

Andrews KS, Tolmieri N, Williams GD, Samhouri JF, Harvey CJ, Levin PS (2011) Comparison of fine-scale acoustic monitoring systems using home range size of a demersal fish. Mar Biol 158:2377-2387. https://doi.org/10.1007/s00227-0111724-5

Austin JA, Lentz SJ (2002) The inner shelf response to winddriven upwelling and downwelling. J Phys Oceanogr 32: 2171-2193

Barnett A, Abrantes KG, Stevens JD, Semmens JM (2011) Site fidelity and sex-specific migration in a mobile apex predator: implication for conservation and ecosystem dynamics. Anim Behav 81:1039-1048

Bell AM, Sih A (2007) Exposure to predation generates personality in three-spined sticklebacks (Gasterosteus aculeatus). Ecol Lett 10:828-834

Berger AM, Arnold L, Rodomsky BT (2015) Status of Kelp Greenling (Hexagrammos decagrammus) along the Oregon Coast in 2015 Pacific Fishery Management Council. Portland, OR:1-207 http://www.pcouncil. org/groundfish/stock-assessments/

Berger AM, Goethel DR, Lynch PD, Quinn T, Mormede S, McKenzie J, Dunn A (2017) Space oddity: the mission for spatial integration. Can J Fish Aquat Sci 74(11):1698-1716. https://doi.org/10.1139/cjfas-2017-0150

Beyer HL (2015) Geospatial Modelling Environment (Software Version 0.7.4.0). http://www.spatialecology.com/gme/

Bryars S, Rogers P, Huveneers C, Payne N, Smith I, McDonald B (2012) Small home range in southern Australia's largest resident reef fish, the western blue groper (Acherodus gouldii): implications for adequacy of no-take marine protected areas. Mar Freshw Res 63:552-563

Burnham KP, Anderson DR (2004) Multimodel inference: understanding AIC and BIC in model selection. Sociol Methods Res 33(2):261-304. https://doi.org/10.1177 /0049124104268644

Buston PM (2004) Territory inheritance in clownfish. Proc R Soc Long B Suppl 4:252-254

Checkley DM Jr, Barth JA (2009) Patterns and processes in the California Current System. Prog Oceanogr 83(1-4):49-64. https://doi.org/10.1016/j.pocean.2009.07.028

Core Team R (2018) R: A language and environment for statistical computing. R Foundation for Statistical Computing, Vienna, Austria https://www.r-project.org/

Crossin GT, Heupel MR, Holbrook CM, Hussey NE, LowerreBarbieri SK, Nguyen VM, Raby GD, Cooke SJ (2017) Acoustic telemetry and fisheries management. Ecol Appl 27:1031-1049

Dance MA, Moutlon DL, Furey NB, Rooker JR (2016) Does transmitter placement or species affect detection efficiency of tagged animal in biotelemetry research? Fish Res 183:8085. https://doi.org/10.1016/j.fishres.2016.05.009

Diaz RJ, Rosenberg R (1995) Marine benthic hypoxia: a review of its ecological effects and the behavioural responses of benthic macrofauna. Oceanogr Mar Biol Annu Rev 33:245-303

Dick EJ, Berger A, Bizzaro J, Bosley K, Cope J, Field J, GilbertHorvath L, Grunloh N, IvensDuran M, Miller R, PriviteraJohnson K, Rodomsky BT (2017) The combined status of blue and deacon rockfishes in U.S. waters off California and Oregon in 2017. Pacific Fishery Management Council, Portland, OR. http://www.pcouncil.org/groundfish/stockassessments/

Dypvik E, Røstad A, Kaartvedt S (2012) Seasonal variations in vertical migration of glacier lanternfish, Benthosema glaciale. Mar Biol 159:1673-1683

Egli DP, Babcock RC (2004) Ultrasonic tracking reveals multiple behavioural modes of snapper (Pagurus auratus) in a temperate no-take marine reserve. ICES J Mar Sci 61:1137-1143

Engelhard GH, van der Kooji J, Bell ED, Pinnegar JK, Blanchard JL, Mackinson S, Righton DA (2008) Fishing mortality versus natural predation on diurnally migrating sandeels Ammodytes marinus. Mar Ecol Prog Ser 369:213-227

ESRI 2015 (2015) ArcGIS Desktop: Release 10.3 Redlands, CA: Environmental Systems Research Institute

Frable B, Wagman DW, Frierson T, Aguilar A, Sidlauskas BL (2015) A new species of Sebastes (Scorpaeniformes: Sebastidae) from the northeastern Pacific, with a redescription of the Blue Rockfish, S. mystinus (Jordan and Gilbert, 1881). Fish Bull 113:355-377. https://doi.org/10.7755 /FB.113.4.1

Furse JB, Davis LJ, Bull LA (1996) Habitat use and movements of largemouth bass associated with changes in dissolved oxygen and hydrology in Kissimmee River, Florida. Proc Annu Conf Southeast Assoc Fish and Wildl Agencies 50:12-25

Galuardi B, Royer F, Golet W, Logan J, Neilson M, Lutcavage M (2010) Complex migration routes of Atlantic Bluefin tuna (Thunnus thynnus) question current population structure paradigm. Can J Fish Aquat Sci 67. https://doi.org/10.1139/F10033

Grantham BA, Chan F, Nielsen KJ, Fox DS, Barth JA, Huyer A, Lubchenco J, Menge BA (2004) Upwelling-driven nearshore 
hypoxia signals ecosystem and oceanographic changes in the northeast Pacific. Nature 429:749-754. https://doi. org/10.1038/nature02605

Gray JS, Wu RS, Or YY (2002) Effects of hypoxia and organic enrichment on the coastal marine environment. Mar Ecol Prog Ser 238:249-279. https://doi.org/10.3354/meps238249

Green KM, Greenley AP, Starr RM (2014) Movements of Blue Rockfish (Sebastes mystinus) off central California with comparisons to similar species. PLoS One 9(6):e98976. https://doi.org/10.1371/journal.pone.0098976

Hannah RW, Blume MTO (2016) Variation in the effective range of a stereo-video lander in relation to near-seafloor water clarity, ambient light and fish length. Mar Coast Fish 8:6269. https://doi.org/10.1080/19425120.2015.1135222

Hannah RW, Rankin PS (2011) Site fidelity and movement of eight species of Pacific Rockfish at a high-relief rocky reef on the Oregon coast. N Amer J of Fish Mgt 31:483-494. https://doi.org/10.1080/02755947.2011.591239

Hannah RW, Parker SJ, Matteson KM (2008) Escaping the surface: the effect of capture depth on submergence success of surface-released Pacific rockfish. North Am J Fish Manage 28(3):694-700. https://doi.org/10.1577/M06-291.1

Hannah RW, Rankin PS, Blume MTO (2012) Use of a novel cage system to measure post recompression survival of northeast Pacific rockfish. Mar Coast Fish 4:46-56. https://doi. org/10.1080/19425120.2012.655849

Hannah RW, Wagman DW, Kautzi LA (2015) Cryptic speciation in the Blue Rockfish (Sebastes mystinus): age, growth and female maturity of the Blue-Sided Rockfish, a newly identified species, from Oregon waters. Oregon Dept Fish Wildl, Information Rept Ser Fish 2015(01):24

Hansen LP, Jonsson N, Jonsson B (1993) Oceanic migration in homing Atlantic salmon. Anim Behav 45:927-941

Hartig F (2020) DHARMa: Residual diagnostics for hierarchical (multi-level/mixed) regression models. $\mathrm{R}$ package version 0 (3):3.0

Hays GC, Ferreira LC, Sequeira AMM, Meekan MG, others (2016) Key questions in marine megafauna movement ecology. Trends Ecol Evol 31:463-475

Hobson RD (1972) Surface roughness in topography: quantitative approach. In: Chorley RJ (ed) Spatial analysis in geomorphology. Harper and Row, New York, New York, USA, pp 221-245

Hobson ES, Chess JR (1988) Trophic relations of the blue rockfish, Sebastes mystinus, in a coastal upwelling system off northern California. Calif Dept Fish Game Fish Bull 86(4): 715-743

Hobson ES, Chess JR, Howard DF (1996) Zooplankters consumed by Blue Rockfish during brief access to a current off California's Sonoma coast. Calif Dept Fish Game Fish Bull 82:87-92

Hopkins TD, Eldridge MB, Cech JJ (1995) Metabolic costs of viviparity in yellowtail rockfish, Sebastes flavidus. Environ Biol Fish 43:77-84. https://doi.org/10.1007/BF00001819

Huyer A, EJC S, Smith RL (1979) The spring transition in currents over the Oregon continental shelf. J Geophys Res 84:69957011

Kim IN, Chang YJ, Kwon JY (1995) The patterns of oxygen consumption in six species of marine fish. J Korean Fish Soc 28:373-381
Kraus R, Wells RJD, Rooker JR (2011) Horizontal movement of Atlantic blue marlin (Makaira nigricans) in the Gulf of Mexico. Mar Biol 158:699-713

Leggett WC (1977) The ecology of fish migrations. Annu Rev Ecol Syst 8:285-308

Nakanishi T, Itazawa Y (1974) Effects of hypoxia on the breathing rate, heart rate and rate of oxygen consumption in fishes. Rep Fish Res Lab Kyushu Univ

Ogburn MB, Harrison A, Whoriskey FG, Cooke SJ, Flemming JEM, Torres LG (2017) Addressing challenges in the application of animal movement ecology to aquatic conservation and management. Front Mar Sci 16. https://doi.org/10.3389 /fmars.2017.00070

Palsson WA, Pacunski RE, Parra TR, Beam J (2008) The effects of hypoxia on marine fish populations in southern Hood Canal, Washington. Am Fish Soc Symp 64:255-280

Parker SJ, Rankin PS, Olson JM, Hannah RW (2007) Movement patterns of black rockfish (Sebastes melanops) in Oregon coastal waters. In: Heifetz J, Di Cosimo J, Gharrett AJ, Love MS, O'Connell VM, Stanley RD (eds) Biology, assessment, and management of North Pacific rockfishes. Alaska Sea Grant College Program, AK-SG-7-01, pp 39-58 https://seagrant.uaf.edu/bookstore/pubs/item.php?id=11233

Parker SJ, Olson JM, Rankin PS, Malvitch JS (2008) Patterns in vertical movements of black rockfish Sebastes melanops. Aquat Biol 2:57-65. https://doi.org/10.3354/ab00036

Patrick WS, Spencer P, Link J, Cope J, Field J, Kobayashi D, Lawson P, Gedamke T, Cortes E, Ormseth O, Bigelow K, Overholtz W (2010) Using productivity and susceptibility indices to assess the vulnerability of United States fish stocks to overfishing. Fish Bull 108:305-322

Peer AC, Miller TJ (2014) Climate change, migration phenology, and fisheries management interact with unanticipated consequences. N American J Fish Man 34:94-110

Pihl L, Baden SP, Diaz RJ (1991) Effects of periodic hypoxia on distribution of demersal fish and crustaceans. Mar Biol 108: 349-360. https://doi.org/10.1007/BF01313644

Pinheiro JC, Bates DM (2000) Mixed effects models in S and SPLUS. Springer, New York, New York. https://doi. org/10.1007/BF01313644

Pittman, S.J. and McAlpine, C.A. (2003) Movements of marine fish and decapod crustaceans: process, theory and application. In: Advances in marine biology, Vol. 44 (eds. A.J. Southward, P.A. Tyler, L.A. Fuiman and C.M. Young), Academic Press, Elsevier, London, U.K., pp. 205-294

Rankin PS, Hannah RW, Blume MTO (2013) Effect of hypoxia on rockfish movements: implications for understanding the roles of temperature, toxins and site fidelity. Mar Ecol Prog Ser 492:223-234. https://doi.org/10.3354/meps10479

Rankin PS, Hannah RW, Blume MTO, Miller-Morgan JT, Heidel JR (2016) Delayed effects of capture-induced barotrauma on physical condition and behavioral competency of recompressed Yelloweye Rockfish, Sebastes ruberrimus. Fish Res 186:258-268. https://doi.org/10.1016/j. fishres.2016.09.004

Rasmuson LK, Lawrence KA, Krutzikowsky GK, Watson JL, Aylesworth L, Hannah RW, Rodomsky BT, Huntington B, Matteson K, Easton RR (2020) Nine years of video landers at the Oregon Department of Fish \& Wildlife's Marine Resources Program. Oregon Dept Fish Wildl, Information Rept Ser Fish 2020(01):274 
Reilly CRL, Thompson SH (2007) Temperature effects on lowlight vision in juvenile rockfish (Genus Sebastes) and consequences for habitat utilization. J Comp Physiol A 193:943953. https://doi.org/10.1007/s00359-007-0247-5

Sappington JM, Longshore KM, Thomson DB (2007) Quantifying landscape ruggedness for animal habitat analysis: a case study using Bighorn Sheep in the Mojave Desert. J Wildl Manag 71:1419-1426. https://doi.org/10.2193/2005723

Sbragaglia V, Nuñez JD, Dominoni D, Coco S, Fanelli E, Azzurro E, Marini S, Nogueras M, Ponti M, del Rio Fernandez J, Aguzzi J (2019) Annual rhythms of temporal niche partitioning in the Sparidae family are correated to different environmental variables. Scientific Reports 9: https://doi. org/10.1038/s41598-018-37954-0

Stanley RD, Kieser RK, Leaman BM, Cooke KG (1999) Diel vertical migration by yellowtail rockfish, Sebastes flavidus, and its impact on acoustic biomass estimation. Fish Bull 97: 322-331

Strub J, James C (1988) Atmospheric conditions during the spring and fall transitions in the coastal ocean off Western United States. J Geophys Res 93:15561-15584

Tolimieri N, Andrews K, Williams G, Katz S, Levin PS (2009) Home range size and patterns of space use by lingcod, copper rockfish and quillback rockfish in relation to diel and tidal cycles. Mar Ecol Prog Ser 380:229-243

van Ginneken V, Antonissen E, Müller UK, Booms R, Eding E, Verreth J, van den Thillart G (2005) Eel migration to the
Sargasso: remarkably high swimming efficiency and low energy costs. J Exp Biol 208:1329-1335

Vaux F, Rasmuson LK, Kautzi LA, Rankin PR, Blume MTO, Lawrence KA, Bohn S, O’Malley KG (2019) Sex matters: otolith shape and genomic variation in deacon rockfish (Sebastes diaconus). Ecol Evol 9:13153-13173. https://doi. org/10.1002/ece3.5763

Wood SN (2004) Stable and efficient multiple smoothing parameter estimation for generalized additive models. J Am Stat Assoc 99:673-686. https://doi.org/10.1198 /016214504000000980

Wood SN (2011) Fast stable restricted maximum likelihood and marginal likelihood estimation of semiparametric generalized linear models. J R Stat Soc Ser B 73(1):3-36. https://doi. org/10.1111/j.1467-9868.2010.00749.x

Zuur AF, Ieno EN, Walker NJ, Saveliev AA, Smith GM (2009) Mixed effects models and extensions in ecology with R. Springer, New York, New York

Zuur AF, Ieno EN, Elphick CS (2010) A protocol for data exploration to avoid common statistical problems. Methods Ecol Evol 1(1):3-14. https://doi.org/10.1111/j.2041-210 X.2009.00001.x

Publisher's note Springer Nature remains neutral with regard to jurisdictional claims in published maps and institutional affiliations. 